how the comparison is made. The plan for a national network for the transmission of data over telephone lines, which is being put forward by a computer group at the National Physical Laboratory (Nature, 218, 806; 1968), was also aired at Edinburgh.

The new ICL machine, the $1908 \mathrm{~A}$, is the latest member of the 1900 series. By juggling with the component parts of the 1908A, so that it has two central processors instead of one, it can be made available as a single system having up to twenty times the power of Atlas-the biggest British computer at present. So far, two 1908As have been spoken for, both by the Computer Board, a government body which promotes the use of computers in the universities and research councils. These two machines are expected to be ready for delivery in 1972, when they will presumably form the nucleus of computing facilities available to the universities in the 1970s. The question of what large computers the Computer Board has been going to buy now seems to be settled, and the board must be pleased that it has been able to order British machines.

The design of the 1908A is based on earlier members of the 1900 series, principally the 1906A which was announced in September last year. Two 1906A machines have already been ordered by the Computer Board. The superior power of the 1908A compared with Atlas lies in its use of high speed integrated circuits and a fast main store based on thin film techniques.

The system for data transmission now being developed by the National Physical Laboratory is to improve the link between the computer and its remote users. A smaller version of part of the proposed network is being built at the NPL where it will serve as an internal data transmission service within the laboratory complex, and as a test of the design of the network. The advantage of a network such as this is that it makes more efficient use of existing telephone lines than present means of data transmission, like the Datel system run by the Post Office. In essence, the new system envisaged by the NPL has computers at the intersections of the telephone lines to control the switching of data to its destinations, and each block of data contains information about its source and its destination, so that data can be transmitted rapidly from place to place. Such a network for high speed data communication, linking twenty towns, would cost perhaps $£ 10$ million. A system such as this is becoming attractive now that much of the cost of using multiaccess computers - for the more remote user at least-is in the price of the trunk call to the machine. Customers who are well away from the computer bureaux in London pay $\mathfrak{E} 3$ per hour for the trunk call to the computer, while the charge for using the computer itself, in the case of Time Sharing Ltd, is about $£ 6$ per hour. For this reason Time Sharing Ltd is discussing with the Post Office a plan to bring all the data from its customers in the Manchester area to its London computer along a single private line. This involves a multiplexer at the Manchester end to interleave the data from the various sources before transmitting it to London.

None too soon, the Post Office has become aware of the way the demand for data transmission facilities is expanding, and together with the Ministry of Technology is starting a study of the services which will be required in the future. A market survey of the demand for data transmission services over the next fifteen years is to be carried out for the Post Office in the next eight months by a firm of consultants, Scientific Control Systems Ltd, who will report the results to the Post Office research and development teams.

Now that a plethora of separate data communication networks is being set up, by the banks and the airlines, for example, this news from the GPO is welcome.

\section{Space Race for the Poor}

WhateVer advantages the distant future may offer from the manned exploration of space, it is clear that the present benefits of the space race are few and far between. For one thing, rich countries have a lot less money to spare for aid to developing countries. For another, the American space effort with its exorbitant demands on scientific manpower is a major sink for the brain drain, a phenomenon which hurts the developing countries far more than it does European ones.

The United Nations, unable to stop the space race or its side effects, has now apparently decided to placate the juggernaut by saying what a good thing it is. A fortnight's conference is being held this month in Vienna under the title "Space Science and Technology-Benefits to Developing Countries". The introductory pamphlet to the conference describes in a style of sustained optimism the cornucopia of technological blessings which future satellite systems will rain down on the poor and rich alike.

In the near future, reflector satellites will shed light on the night earth, the pamphlet says, and "by providing illumination for construction, lumbering, fishing and other outdoor industries, could conceivably have an important effect on the economic growth of the developing nations". The pamphlet does not discuss the catastrophic effect of such a satellite on biological rhythms, nor does it explain in what manner nighttime fishing and lumbering will boost any nation's economy. Limited by its title to discussing only the benefits of the space race, the pamphlet aroids any discussion of its economic consequences. Predictions of future benefits are supported by liberal quotations from Arthur C. Clarke and unnamed experts. As a preview to a conference, the pamphlet seems more fitted to a convention of science fiction writers than a meeting to discuss the needs of developing countries.

The agenda for the conference does little to inspire the hope that the needs of poorer nations will be heard. Of nearly 200 addresses, a mere 11 are to be delivered by speakers from developing countries. A considerable part of the conference's attention will be devoted to communications satellites but without, apparently, discussing the question of the allocation of parking orbits for synchronous satellites or a wider membership for COMSAT. The only comment the pamphlet can offer is that "international cooperation in space is obviously a very complicated problem", too complicated, evidently, for the conference to risk dissension in discussing it. Since almost all questions of importance are excluded from the agenda of the conference, the developing countries can expect very little good from it; they are unlikely in any case to be persuaded that the space race has anything but harm to offer to them in present circumstances. 